\title{
COMPARATIVE CFD BASED PARAMETRIC ANALYSIS OF GAS FLOW IN TWO CONTER-FLOW WET SCRUBBER SYSTEMS
}

\author{
Daniela-Elena Jugănaru', Mariana Panaitescu' ${ }^{1}$, Liviu-Constantin Stan ${ }^{1}$ \\ ${ }^{1}$ Constanta Maritime University, Faculty of Naval Electro-Mechanics, 104 Mircea cel Batran Street, 900663, Constanta, \\ Romania, e-mail dana.mitu@cmu-edu.eu
}

\begin{abstract}
In this study, gas flow field were simulated using ANSYS 2020R2, Fluid Flow Fluent computational fluids dynamic (CFD) software based on the continuity, velocity, temperature, energy and $\mathrm{k}-\varepsilon$ turbulence. The overall objective of the study is to compare the pressure and velocity maps inside the wet scrubber system for two different scrubber designs. I have choose to analyse an In-Line scrubber bottom inlet, type I, and In-Line scrubber side inlet, type L. Bottom entry or side entry designs to allow a direct up-flow configuration and simplify engine exhaust gas duct routing for any type of vessel. The flow in a wet scrubber is very complex due to the interaction between dust particles, water droplets, and bulk water and flue gas. The flue gas flow is turbulent and there are multiple phases (gas, liquid and solid).

CFD codes that predict gas flow patterns are based on conservation equations for mass, momentum and energy.

The results show that the residuals have a very good job of converging at minimum flow contours and vectors at the inlet across the scrubbing chamber and outlet shows a distributed flow. The velocity profiles have fully conformed to the recommended profile for turbulent flow in pipes.

As can be seen in the figures above, the velocity flow contour inside the scrubber is higher in the scrubber side inlet.

Even though I choose to study the simplified scrubber model without taking into account that spray nozzle improve mixing between the scrubbing liquid and waste gas; from the results obtained, it can be deduced that the numerical simulation using CFD is an effective method to study the flow characteristics of a counter-flow wet scrubber system.
\end{abstract}

Key words : $\boldsymbol{C F D}$, In-Line scrubber bottom inlet, side inlet, velocity contour.

\section{INTRODUCTION AND LEGISLATIVE FRAMEWORK}

The International Maritime Organization (IMO) has decided that all vessels sailing in the Emission Control Areas (ECA) must reduce sulphur level in fuel oil to $0.1 \%$ or clean the exhaust gas to an equivalent level by 2015. According to Marpol Annex VI are the Baltic Sea, the North Sea, North America (covering designated coastal area in the US and Canada) and the US Caribbean Sea (around Puerto Rico and the US Virgin Island). For the other navigable areas, the sulphur content of the fuel for ships has been limited from January 2020 to a maximum of $0,5 \%$. Until this date, the overall sulphur content limit was $3,5 \%$, a level considered easy to meet for ship operators.

With the implementation of IMO 2020, the International Maritime Organization aims to reduce total sulphur emissions from ships by $77 \%$ from 2020 to
2025. The overall goal is to reduce the negative impact of shipping on human health by reducing air pollution by $68 \%$, especially in the coastal areas of Asia-Pacific, Africa and Latin America.

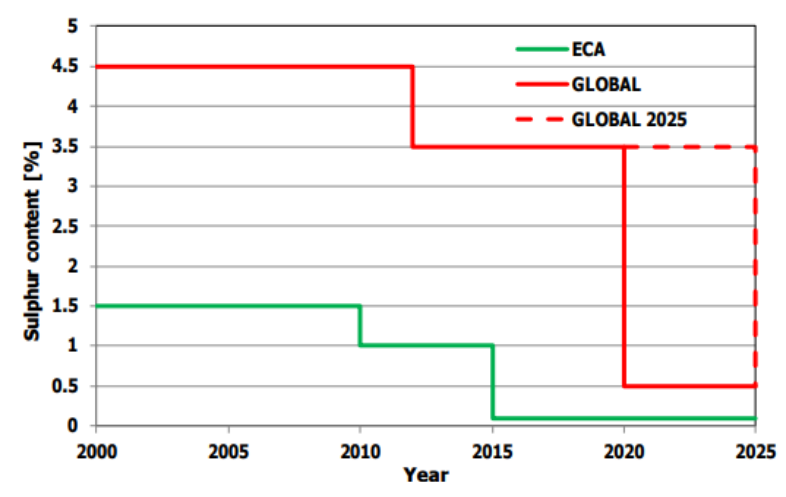

Figure 1 IMO regulation of SOx levels [1] 
Journal of Marine technology and Environment

Ship operators have the following options to comply with the new sulphur content limits under IMO 2020.

The use of exhaust gas cleaning systems, known as gas scrubbers, is a commercially available option for the transport industry. Vessels equipped with gas scrubbers may continue to burn fuel for boilers with a high gas content and thus may comply with the sulphur limit of $0,5 \%$.

Emission reduction technology works by spraying alkaline water into a vessel to remove sulphur and other unwanted chemicals, through an open loop system, a closed loop system or a hybrid system. The use of gas scrubbers will allow the eradication of almost half of ships' harmful emissions.

\section{OBJECTIVES}

The objectives of the paper are to gain an improved understanding of the processes in wet scrubbers. These flow processes include but are not limited to:

- flue gas and droplet flows;

- agglomeration of droplets;

- flow of bulk water

- Interaction between dust particles and water droplets.

With the improved modelling capability, existing scrubber designs can be simulated with the aim of determining design modifications for improved scrubber performance.

The aims of this study was to simulate the gas flow fields using ANSYS 2020R2, Fluid Flow Fluent computational fluids dynamic (CFD) software based on the continuity, velocity, temperature, energy and $\mathrm{k}-\varepsilon$ turbulence. The overall objective of the study is to compare velocity maps inside the wet scrubber system by vector, contour and streamlines for two different InLine scrubbers, one with bottom inlet designs and other with side-inlet design.

\section{THEORETICAL NOTIONS}

The general approach to the study was to rationalize scrubber performance in terms of basic principles.

Scrubbers are used to control emissions from many diversified sources and are favoured over other air pollution control equipment under the following circumstances:

- Where the removal of gaseous, or simultaneous gaseous and particulate contaminants is required.

- Where the treatment or disposal of the liquid effluent is simple and not expensive.

- Where there is no water shortage.

- Where available plant space is limited.

- Where there is an explosion hazard.
Year 2021, Vol.I

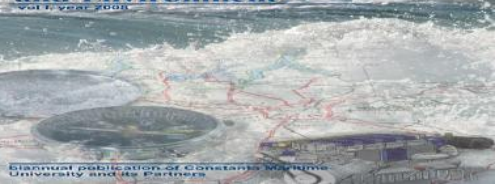

- Where dust resistivity and/or gas temperature is high.

- Where the dust particles are larger than $5 \mu \mathrm{m}$.

- Where the gas is at or above the dew point.

- Above all, where the economics is favourable. [2]

\subsection{Seawater desulfurization system for marine industry}

Using seawater as a desulfurization absorbing liquid, our marine SOx scrubber employs a seawater desulfurization system that has a simple configuration and can be installed in a limited space. The system flow diagram of marine SOx scrubber is presented in figure 1. The seawater taken from the sea is supplied to the absorption tower directly spraying into flue gas. The system utilizes alkaline components naturally contained in seawater to remove sulphur. The marine SOx scrubber complies with the IMO EGCS Guidelines and makes sure that the effluent $\mathrm{pH}$, polycyclic aromatic hydrocarbons (PAHs), turbidity, etc., are within the respective limits before being discharged overboard. Each unit of the marine SOx scrubber needs to be approved by a classification society regarding its compliance with the Guidelines. [3]

IMO allows clean wash water to be discharged overboard in any water area. Clean means:

- turbidity below 25 NTU

- PAH level below 50 ppb

- $\mathrm{pH} 6.5$ (4 meters from ship). $\mathrm{pH}$ can be measured after correction or dilution.

\subsection{Conditions influencing on the design of scrubber system}

In principle, an EGC (exhaust gas cycle) scrubber system can be fitted on any type of ship sailing in any ocean in the word, but a great importance is given to the factors like sea water temperature, sea water alkalinity, fuel oil quality and engine or boiler type that influence on the dimensions and efficiency of the scrubber. There are three big categories of factors, like: external factors, vessel details and legislation.

External factors are fuel oil type and quality, water quality, air temperature and relative humidity, and sea water temperature.

The factors by the vessel details are: engine type and size; space restrictions and limitations on electrical power. Scrubbers are designed to comply with the guidelines as provided by MEPC under IMO, which are being implemented in EU, US and national legislation by taken into account the sulphur limit and discharge water. [4] 


\section{Journal of Marine technology and Environment}

\section{NUMERICAL MODELING}

In this study, gas flow field were simulated using ANSYS 2020R2, Fluid Flow Fluent computational fluids dynamic (CFD) software based on the continuity, velocity, temperature, energy and $\mathrm{k}-\varepsilon$ turbulence. The overall objective of the study is to compare the pressure and velocity maps inside the wet scrubber system for two different scrubber designs. I have choose to analyse an In-Line scrubber bottom inlet, type I, and In-Line scrubber side inlet, type L. Bottom entry or side entry designs to allow a direct up-flow configuration and simplify engine exhaust gas duct routing for any type of vessel.

ANSYS Fluent is arguably the powerful CFD package for simulating multi-phase flows and was chosen for the modelling work in this paper.

The flow in a wet scrubber is very complex due to the interaction between dust particles, water droplets, bulk water and flue gas. The flue gas flow is turbulent and there are multiple phases (gas, liquid and solid).

CFD codes that predict gas flow patterns are based on conservation equations for mass, momentum and energy. [6]

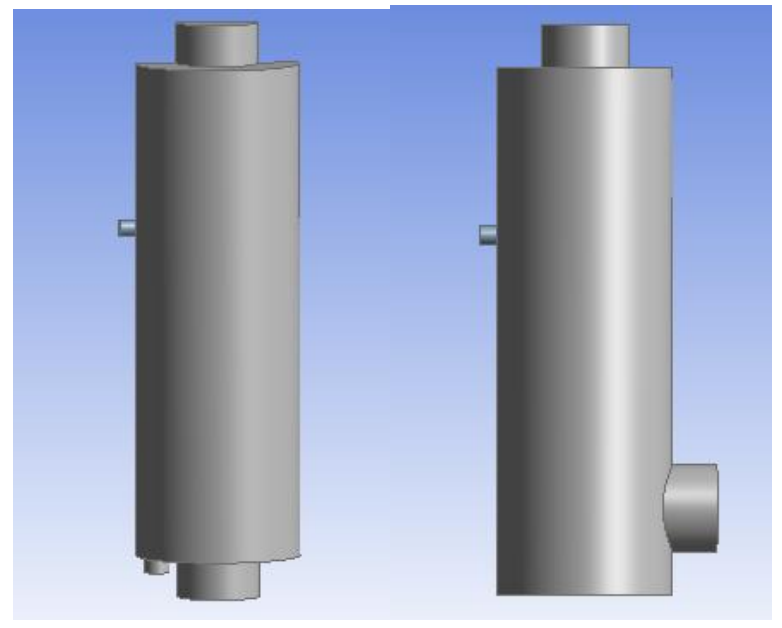

Figure 2 In-Line scrubber bottom inlet and side inlet

Figure 2 shows the three dimensional model of InLine scrubber bottom inlet and In-Line scrubber side inlet. Both models are created in ANSYS 2020R2 and work in Open Loop System.

Table 1 Dimensions of the scrubber analysed

\begin{tabular}{|c|c|}
\hline Part & Value $(\mathrm{cm})$ \\
\hline Scrubber height & 700 \\
\hline
\end{tabular}

\begin{tabular}{|c|c|}
\hline Year 2021, Vol.I & 200 \\
\hline Scrubber diameter & 100 \\
\hline Waste gas inlet diameter & 100 \\
\hline Scrubbing gas outlet diameter & 20 \\
\hline Slurry outlet diameter & 30 \\
\hline
\end{tabular}

Figure 3 shows a schematic of the mesh used. The mesh near the walls are fine, whereas away from the walls and towards the centre are coarser. A total of 412983 quad elements and 89789 nodes were used in the analysis for the first model and 382531 quad elements and 83148 nodes for the second model.

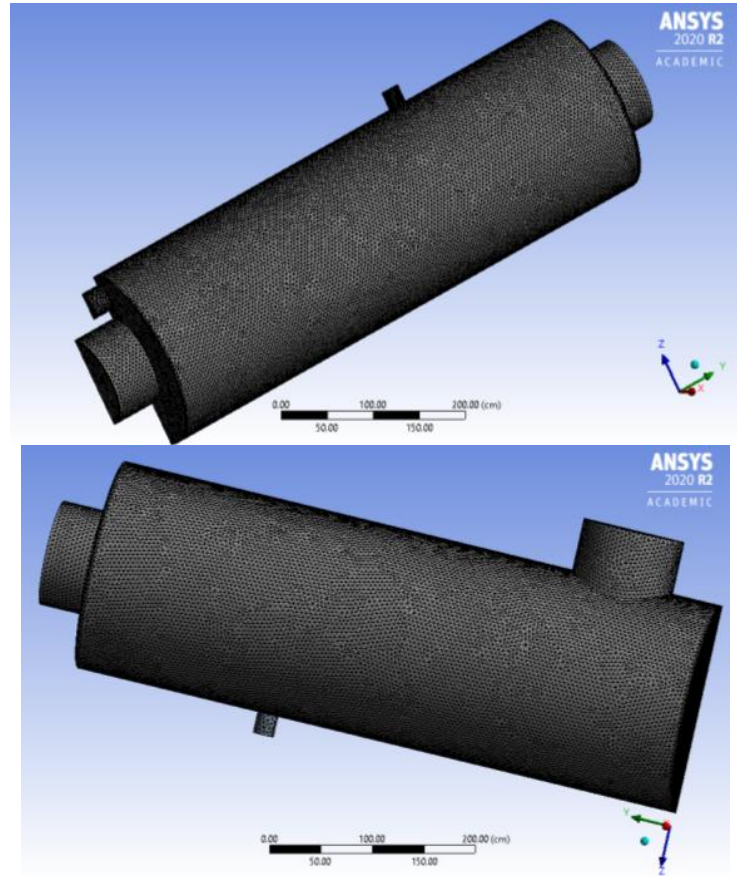

Figure 3 Mesh models

\subsection{Boundary conditions}

Inlet mass flow rate under $100 \%$ engine load was taken $23,72 \mathrm{~kg} / \mathrm{s}$. The pressure for inlet waste gas was $101325 \mathrm{~Pa}$ and the temperature defined was $485 \mathrm{~K}$.

The pressure droplets taken into account in analyse was $1000 \mathrm{~Pa}$ and the temperature was $298 \mathrm{~K}$.

The both models of scrubbers were design with two layers of nozzles inside the scrubber (26 nozzles).

The injection pressure of each nozzle is $0,2 \mathrm{MPa}$ and the spray cone angle is $90^{\circ}$. But in this analyse we chose to eliminate all the details for simplified the simulation. 


\section{Journal of Marine technology and Environment Year 2021, Vol.I}

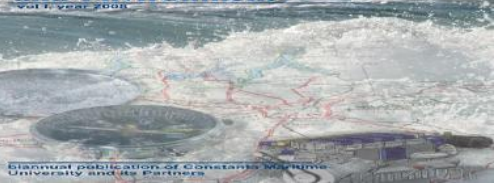

The continuity, velocity, temperature, energy and $\mathrm{k}$ - $\varepsilon$ turbulence for the both cases were represented in the next figure in 50 iterations.

\section{RESULTS}

The results which were analysed are presented below:

- one model with velocity and pressure distributions (Figure 4, Figure 6);

- second model with velocity and pressure distributions (Figure 5, Figure 7.

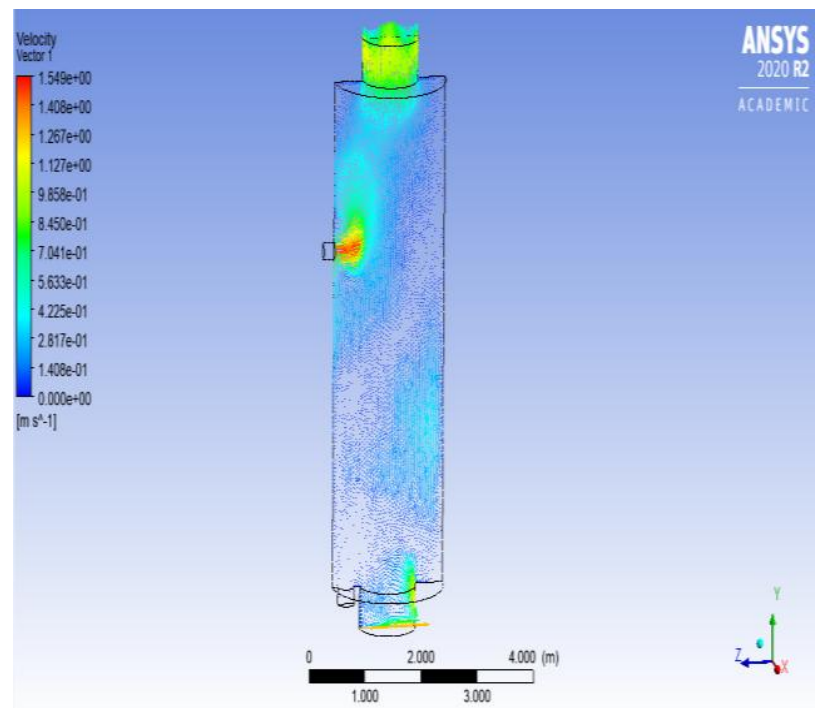

Figure 4 Velocity vector-first model

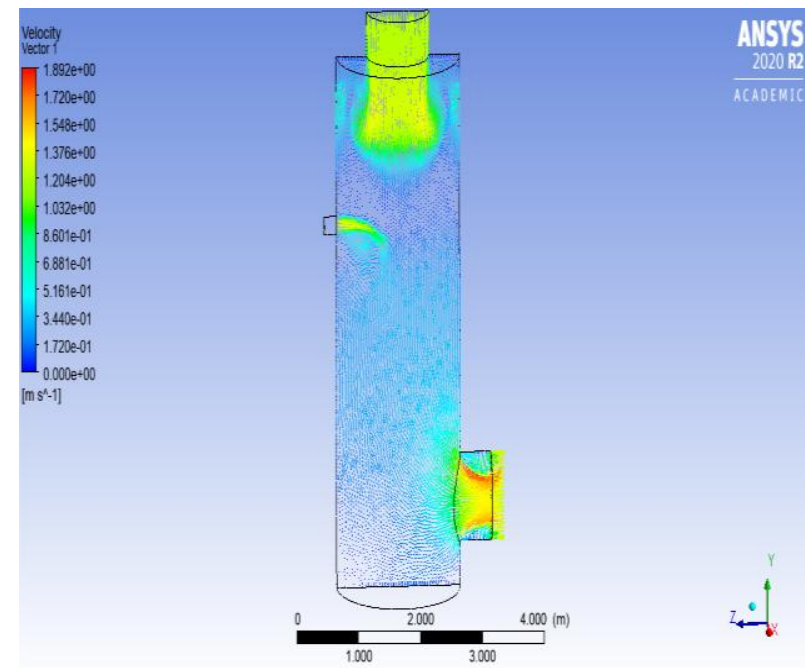

Figure 5 Velocity vector-second model

For the In-Line scrubber bottom inlet, the maximum value of the velocity was $1,5491 \mathrm{~m} / \mathrm{s}$ (Figure 4) and for the other model analysed was $1,892 \mathrm{~m} / \mathrm{s}$. (Figure 5).
For the velocity contour the distributions are presented in Figure 6 and Figure 7 for both models.

For pressure, the minimum value obtain was $183,036 \mathrm{~Pa}$ and the maximum value was $+251,564 \mathrm{~Pa}$ for the In-Line scrubber bottom inlet.

In comparison with this model, for the second one, the values was $-116,021 \mathrm{~Pa}$ and $+204,83 \mathrm{~Pa}$.

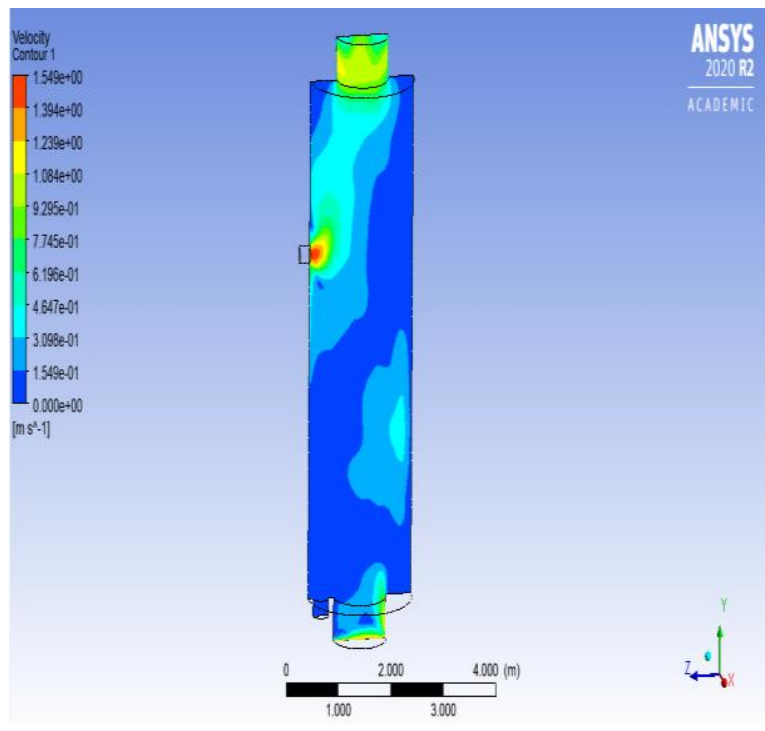

Figure 6 Velocity Contour-first model

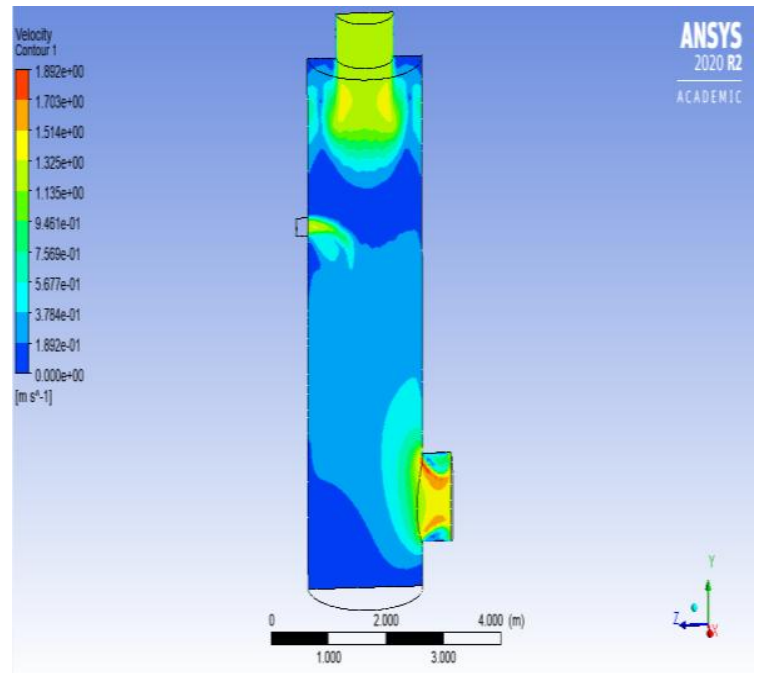

Figure 7 Velocity Contour-second model

The fields of streamline for both models are presented in the Figure 8 and Figure 9. 


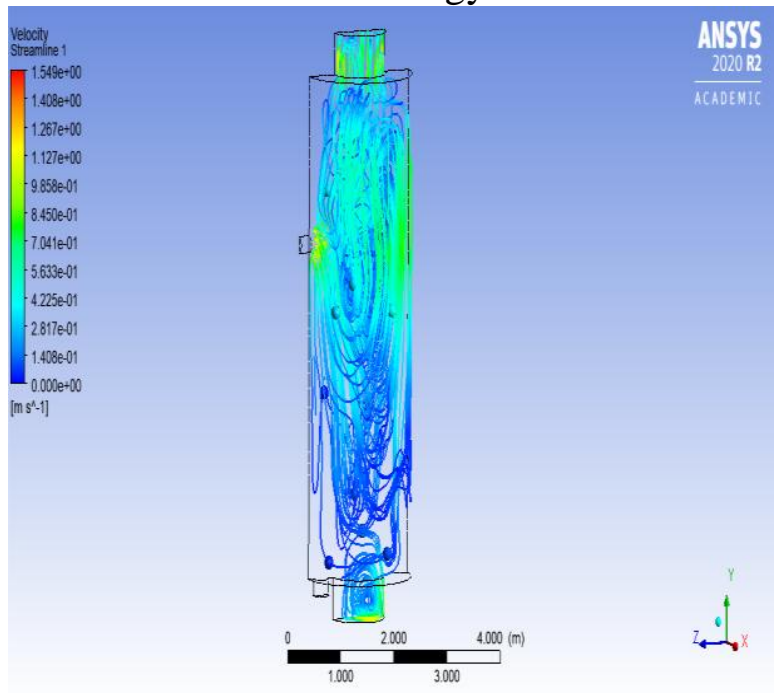

Figure 8 Velocity streamline field model 1

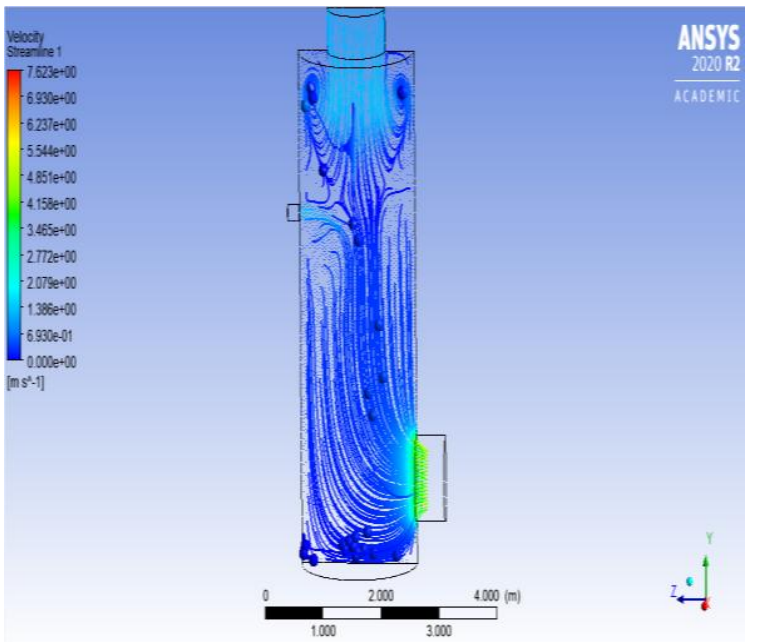

Figure 9 Velocity streamline field model 2

The values for the turbulent kinetic energy $\mathrm{k}$ in the first analyse were between $4,973567 \cdot 10^{-8}$ and 22,106 $\mathrm{m}^{2} / \mathrm{s}^{2}$ and for second analyse were between $3,58187 \cdot 10^{-7}$ and $25,241 \mathrm{~m}^{2} / \mathrm{s}^{2}$.

The total pressure within the scrubber cross-section is constant while the minimum and maximum pressure drops was conformed to the recommended pressure drop for wet scrubber.

\section{CONCLUSIONS}

The results show that the residuals have a very good job of converging at minimum flow contours and vectors at the inlet across the scrubbing chamber and outlet shows a distributed flow. The velocity profiles have fully conformed to the recommended profile for turbulent flow in pipes.

As can be seen in the figures above, the velocity flow contour inside the scrubber is higher in the scrubber side inlet.

The difference in velocity values is maintained at about $0,3 \mathrm{~m} / \mathrm{s}$ through the inner surface of the scrubber. The same difference can be observed at the clean gas outlet.

Even though we choose to study the simplified scrubber model without taking into account that spray nozzle improve mixing between the scrubbing liquid and waste gas; from the results obtained, it can be deduced that the numerical simulation using CFD is an effective method to study the flow characteristics of a counterflow wet scrubber system.

\section{REFERENCES}

[1] Green ship of the future. Vessel emission study: Comparison of various abatement technologies to meet emission levels for ECA's, www.greenship.org

[2] Final report and bibliography, Wet scrubber system study, July 1972 Vol II, Prepared for Environmental Protection Agency, Ed. Apt.

[3] Ryozo S., Tatsuto N., et al., September 2019, Practical design of marine SOx scrubber for megacontainer ships, Vol 56, no 3, Mitsubishi Heavy Industries Technical Review.

[4] Hasen J.P., Kaltoft J., et al., 2014, Reduction of SO2, NOX and particulate matter from ships with diesel engines, Environmental Project no 1510.

[5] Mussatti D., Hemmer P., July 2002, Wet scrubbers for particulate matter, Particulate Matter Controls, , EPA/452/B-02-001.

[6] Bird et al., 1960; Roache, 1976)

[7] Stan L., October 2016, Construction testing of an offshore pipeline using numerical methods, Vol 2, Journal of Marine Technology and Environment. 